\title{
CC-chemokine receptors: a potential therapeutic target for Trypanosoma cruzi-elicited myocarditis
}

\author{
APMP Marino, AA Silva/*, PVA Santos, LMO Pinto, RT Gazinelli**/***, MM Teixeira***, \\ J Lannes-Vieira/ ${ }^{+}$
}

\begin{abstract}
Laboratório de Autoimunidade e Imuno-regulação, Departamento de Imunologia, Instituto Oswaldo Cruz-Fiocruz, Av. Brasil 4365, 21040-900 Rio de Janeiro, RJ, Brasil *Departamento de Patologia, Universidade Federal Fluminense, Niterói, RJ, Brasil **Laboratório de Imunopatologia, Centro de Pesquisas René Rachou-Fiocruz, Belo Horizonte, MG, Brasil ***Departamento de Bioquímica e Imunologia, Universidade Federal de Minas Gerais, Belo Horizonte, MG, Brasil
\end{abstract}

The comprehension of the pathogenesis of Trypanosoma cruzi-elicited myocarditis is crucial to delineate new therapeutic strategies aiming to ameliorate the inflammation that leads to heart dysfunction, without hampering parasite control. The augmented expression of CCL5/RANTES and CCL3/MIP-1 $\alpha$, and their receptor CCR5, in the heart of T. cruzi-infected mice suggests a role for CC-chemokines and their receptors in the pathogenesis of $\mathrm{T}$. cruzielicited myocarditis. Herein, we discuss our recent results using a CC-chemokine receptor inhibitor (Met-RANTES), showing the participation of CC-chemokines in T. cruzi infection and unraveling CC-chemokine receptors as an attractive therapeutic target for further evaluation in Chagas disease.

Key words: Trypanosoma cruzi - myocarditis - CC-chemokines - CC-chemokine receptors - Met-RANTES

Chagas disease is caused by the hemoflagellate protozoan Trypanosoma cruzi, and affects 16-18 million people in South America. Although the establishment of inflammatory processes during the acute infection seems to be crucial for parasite control, about $30 \%$ of patients develop chronic myocarditis with organ dysfunction. In this phase, $\mathrm{CD}^{+} \mathrm{T}$ cells predominate in the intense inflammatory infiltrates, which are not directly related to the rare parasite presence. Trying to explain this phe-nomenon, several hypotheses have associated chronic chagasic myocarditis to autoimmune process (Higuchi et al. 2003). This factor, coupled to control of the main Chagas disease vectors, induced a decline in the research for new drugs that could potentially improve the prognosis of chagasic patients. Therefore, although in the past years many contributions have been made to understand the physiopathology of chagasic myocarditis, new therapeutic approaches besides the already available anti-parasite drugs have not been developed. The major challenge in designing an efficacious treatment for T. cruzi-elicited myocarditis is to develop a strategy able to reduce the intense inflammation, which produces severe tissue damage, without hampering the control of parasitism. In this context, the comprehension of the pathogenesis of disease and the molecules that take part in this process might contribute to delineate new therapeutic strategies. In the last years our group has been studying the cell adhesion molecules, cytokines and chemokines putatively involved in the establishment of T. cruzi-elicited myocarditis (Lannes-

Financial support: Papes-II-Fiocruz, CNPq, Faperj, IOCFiocruz, and fellowship from Capes (APMPM) and CNPq (LMOP, RTG, MMT, JLV).

${ }^{+}$Corresponding author. E-mail: lannes@ioc.fiocruz.br

Received 8 November 2004

Accepted 30 December 2004
Vieira 2003). Herein, we will explore the participation of CC-chemokines and their receptors in T. cruzi-induced myocarditis and bring evidence pointing them as attractive therapeutic targets to modulate the non-beneficial inflammation during chagasic infection.

Chemokines are small (8-14 kDa) constitutive or inducible/inflammatory cytokines. These small proteins comprise four subfamilies (CXC or $\alpha, \mathrm{CC}$ or $\beta, \mathrm{C}$ or $\gamma$ and $\mathrm{CX}_{3} \mathrm{C}$ or $\delta$ ) (Proudfoot 2002). Besides playing a crucial role in normal trafficking of leukocytes to both lymphoid and nonlymphoid organs and recruitment of these cells to sites of injury and infection, chemokines and their receptors have been shown to affect various biological events including T-cell proliferation (Taub et al. 1993), Th1/Th2 differentiation (Gao et al. 1997), and resistance to infection (Machado et al. 2000, Proudfoot 2002, Teixeira et al. 2002).

Several studies have shown that $T$. cruzi-infected human and mouse macrophages (Villalta et al. 1998, Aliberti et al. 1999) as well as cardiomyocytes (Machado et al. 2000) produce the CC-chemokines CCL5/RANTES, CCL3/ MIP-1 $\alpha$, CCL4/MIP-1 $\beta$ and CCL2/MCP-1. Further, increased levels of CCL5/RANTES, CCL3/MIP-1 $\alpha$, CCL4/ MIP-1 $\beta$, CCL2/MCP-1 and the CXC chemokines CXCL10/ IP-10 and CXCL9/MIG mRNA have been detected in the heart tissue of acutely and chronically $T$. cruzi-infected mice (Talvani et al. 2000, Aliberti et al. 2001, dos Santos et al. 2001, Marino et al. 2004), implicating a potential role for these molecules in Chagas disease.

Chemokines act on seven trans-membrane spanning G-protein-coupled serpentine receptors expressed on the surface of several cell types, including leucocytes (Proudfoot 2002). Recently, numerous reports have shown the importance of chemokine receptors as co-factors for viral infection and chronic inflammation (Proudfoot et al. 2003). The expression of CCR5 (receptor for CCL5/ RANTES, CCL3/MIP- $1 \alpha$ and CCL4/MIP-1 $\beta$ ) alleles was analyzed in chagasic patients. Interestingly, two 
independent studies have shown that the CCR5-59029G allele, associated with $\mathrm{CCR} 5^{\text {low }}$ expression, is more frequent in asymptomatic as compared with cardiomyophatic T. cruzi-infected patients (Calzada et al. 2001, Fernandez-Mestre et al. 2004). These results indicate a role for this chemokine receptor in the pathogenesis of chagasic cardiomyopathy. Supporting this, increased frequency of CCR5-bearing peripheral blood leukocytes is observed in cardiopathic chagasic patients compared with uninfected individuals. Interestingly, higher frequency of circulating leucocytes expressing CCR5 and CXCR4 (receptor for CXCL12/SDF-1) is detected in patients with mild CCC than in patients with severe CCC, that present frequency of CCR5-bearing leukocytes similar to noninfected individuals (Talvani et al. 2004). Also, in chronically $T$. cruzi-infected rhesus monkeys the asymptomatic form of the disease was associated with high frequency of $\mathrm{CCR}^{+}$peripheral blood leukocytes, while decreased frequencies of $\mathrm{CCR} 5^{+}$circulating leukocytes, similar to those found in noninfected monkeys, were directly associated with increased heart dysfunction (Carvalho et al. unpublished data). Thus, the lower frequency of $\mathrm{CCR} 5^{+}$peripheral blood leukocytes in chagasic individuals with more severe disease can be due to the presence of heart dysfunction. Moreover, it has been reported that $\mathrm{T}$ cells present in the heart of T. cruziinfected mice, mostly CD8 ${ }^{+}$, express CCR5 (Teixeira et al. 2002, Marino et al. 2004). Altogether, these data favor a relevant pathophysiological role for CCR5 and its ligands in $T$. cruzi-triggered myocarditis. Therefore, it is tempting to speculate that CCR5-bearing peripheral blood leukocytes differentially migrate to the heart of $T$. cruziinfected individuals and take part in the genesis of tissue damage resulting in organ dysfunction. This idea is presently under investigation.

Several studies have demonstrated that $\mathrm{CD} 8^{+}$ lymphocytes are the predominant cell population in the cardiac tissue of chronic chagasic patients (D'avila Reis et al. 1993, Higuchi et al. 1997, Reis et al. 1997). Studying $\mathrm{C} 3 \mathrm{H} / \mathrm{He}$ mice chronically infected with the Colombiana strain of $T$. cruzi we showed the prevalence of $\mathrm{CD} 8^{+} \mathrm{T}$ cells in the inflamed heart (dos Santos et al. 2001). Further, recently we have shown that the establishment of the $\mathrm{CD}^{+}{ }^{+}$cells predominance in the cardiac tissue of T. cruziinfected mice is a rather precocious process, being detected during the early acute phase (Marino et al. 2003a). Trying to understand the molecular mechanisms involved in T. cruzi-elicited myocarditis with prevalence of $\mathrm{CD} 8^{+} \mathrm{T}$ cells, we have investigated the expression of inflammatory CC-chemokines in the heart of Colombiana straininfected $\mathrm{C} 3 \mathrm{H} / \mathrm{He}$ mice. Interestingly, increased expression of CCL2, CCL3, CCL4 and CCL5 was observed during the acute and chronic phases (dos Santos et al. 2001, Marino et al. 2004). These CC-chemokines are described to attract activated leukocytes, preferentially $\mathrm{CD} 8^{+} \mathrm{T}$ cells (Sallusto 1998, Cook et al. 1999). Thus, this chemokine profile could explain the prevalence of $\mathrm{CD}^{+} \mathrm{T}$ lymphocytes in the cardiac tissue of T. cruzi-infected mice. Further, these CC-chemokines could be involved in T. cruzi growth control, enhancing parasite uptake and nitric oxide (NO) production (Villalta et al. 1998, Aliberti et al. 1999,
Machado et al. 2000). In contrast, these CC-chemokines could also contribute to pathogenesis, increasing NO production and inducing fibrosis and tissue damage. In this vein, CCL2/MCP-1 and its receptor CCR2 were shown to play a pivotal role in cardiac fibrosis and heart failure (Hayashidani et al. 2003). In Chagas disease, an intense fibrosis is associated to congestive cardiac failure (Higuchi et al. 2003) and there is also a good correlation between CCL2 plasma levels and the degree of heart dysfunction in cardiopathic chagasic patients (Talvani et al. 2004). Moreover, the CC-chemokines could be crucially driving the establishment of inflammatory processes in the cardiac tissue of T. cruzi-infected in-dividuals. To shed light on this question, we analyzed the production of these chemokines in the early phase of the infection. In fact, CCL2, CCL3, CCL5, and, in lesser extend, CCL4 are enhanced as early as 28 days pot-infection, paralleling the leukocyte influx, mainly composed of $\mathrm{CD} 8^{+} \mathrm{T}$ cells, into the cardiac tissue (Marino et al. 2004). Most of these inflammatory cells infiltrating the cardiac tissue of infected mice are CCR5-bearing mononuclear cells. Importantly, CCR5 frequency and density (characterized as increased mean fluorescence intensity) are up-regulated in splenocytes and peripheral blood leukocytes of T. cruziinfected animal as early as 7 days post-infection (Silva et al. unpublished data). Moreover, at 28 days post-infection this alteration is mainly found among $\mathrm{CD} 8^{+} \mathrm{T}$ cells, suggesting that CCR5 and its ligands might be important in the preferential entrance of $\mathrm{CD} 8^{+} \mathrm{T}$ cells into the heart tissue (Marino et al. 2004). Altogether, these data favor a relevant pathophysiological role of CCR5-mediated interactions (CCL5/CCR5, CCL4/CCR5 and CCL3/CCR5) in $T$. cruzi-triggered myocarditis. To test this hypothesis, we treated T. cruzi-infected mice with Met-RANTES, an amino-terminally modified RANTES analogue, that exhibits inhibitory properties on leukocyte chemotaxis (Proudfoot et al. 1996, 1999). Previous studies have shown the efficacy of Met-RANTES in the control of inflammation in diverse pathologies, such as skin allergy, arthritis, and renal transplant rejection (Teixeira et al. 1997, PlaterZyberk et al. 1997, Gröne et al. 1999). The treatment of acutely $T$. cruzi-infected mice with Met-RANTES was beneficial, increasing the survival of animals compared with saline-injected mice. Importantly, inflammation was inhibited in about $60 \%$, mainly due to reduction in the numbers of $\mathrm{CCR}^{+}$, especially $\mathrm{CD} 8^{+}$and $\mathrm{CD} 4^{+} \mathrm{T}$ cells, while the numbers of cells bearing Mac-1 (a marker for macrophages, granulocytes and NK cells) were not significantly modified. Despite the recent report showing that administrating of Met-RANTES during herpes simplex virus type 2 infection impairs host defense (Sorensen \& Paludan 2004), during T. cruzi infection the Met-RANTESinduced reduction of acute inflammation did not hamper parasite control (Marino et al. 2004). Considering that activated macrophages, $\mathrm{CD} 4^{+}$and $\mathrm{CD} 8^{+} \mathrm{T}$ cells play a crucial role in the control of parasite replication (Russo et al. 1991, Tarleton et al. 1994, Aliberti et al. 1999), our results indicate that the massive influx of inflammatory cells, especially $\mathrm{CCR}^{+}$cells, into the cardiac tissue is not crucial for cell-mediated anti-T. cruzi immunity. Interestingly, in Met-RANTES-treated infected mice the numbers of IFN- 
$\gamma^{+}$and TNF- $\alpha^{+}$cells were unaltered (Marino et al. 2004). This is in agreement with the relevance of these cytokines for parasite control and the lack of effect of Met-RANTES on tissue parasitism. Further, considering the protein expression, Met-RANTES treatment did not modify the levels of CCL5/RANTES and CCL2/MCP-1, while the expression of CCL3/MIP-1 $\alpha$ was slightly down-modulated (Marino et al. unpublished data). Although slight, the decreased expression of CCL3/MIP-1 $\alpha$ might be related with the decreased numbers of $\mathrm{CD} 8^{+}$cells into the heart tissue of Met-RANTES-treated infected mice, as these cells are the main producers of this chemokine (Cook et al. 1999). On the other hand, the fact that T. cruzi-infected cardiomyocytes and macrophages produce large amounts of CCL5/RANTES and CCL2/MCP-1 (Machado et al. 2000, Talvani et al. 2000), could explain the finding showing that parasite growth was not hampered in Met-RANTEStreated mice as these CC-chemokines, particularly CCL2/ MCP-1, actively elicit parasite uptake and killing (Aliberti et al. 1999). Altogether, our results point to the fact that this discreet change in chemokine pattern induced by MetRANTES treatment was not sufficient to impair parasite control.

The presence of IL- $4^{+}$cells correlates with the presence of $T$. cruzi antigens in severe chronic chagasic cardiomyopathy (Higuchi et al. 1997, Reis et al. 1997), suggesting that IL-4 is involved in parasite dissemination. Moreover, IL-4-deficient mice had reduced heart parasitism and mortality during acute infection (Michailowisky et al. 2001). Interestingly, an intense reduction in the numbers of IL- $4^{+}$cells paralleled the reduction in the numbers of $\mathrm{CCR}^{+}$cells in the heart of T. cruzi-infected animals treated with Met-RANTES comparing with those receiving vehicle (Marino et al. 2004). Consequently, the reduced numbers of IL-4-producing cells might favor parasitism control and increase of survival in the animals treated with MetRANTES. In addition, IL-4 is an important fibrogenic cytokine (Mckenzie 2000) and fibrosis is associated with T. cruzi-triggered heart dysfunction (Higuchi et al. 2003, Marino et al. 2003b). Interestingly, inhibition of the deposition of the extracellular matrix component fibronectin, previously shown to be increased in the cardiac tissue of infected mice (reviewed by Marino et al. 2003b), was observed in Met-RANTES-treated mice. Nevertheless, fibronectin also favors parasite dissemination (reviewed by Marino et al. 2003b). Further, fibronectin-bound cytokines, particularly TNF- $\alpha$, act as chemotactic and pro-adhesive factors on activated T cells (Vaday et al. 2001). It is tempting to propose that IL-4, besides favoring parasite dissemination, is also inducing cardiac fibrosis in $T$. cruzi infection, although other profibrotic mediators may also participate.

In summary, our results support that Met-RANTES treatment favored the balance towards a Th1 response in the heart. The IFN- $\gamma$ and TNF- $\alpha$ play a major role in modulating chemokine expression and, consequently, the chemokine-mediated leukocyte influx (Aliberti et al. 2001, Lannes-Vieira 2003).The decrease in the numbers of Th2 ${ }^{+}$ cells could be the result of the differential expression of CCR5 $5^{\text {high }}$ by Th1 and CCR $5^{\text {low }}$ by Th2 (Loetscher et al. 1998). It is possible that the Th2 cell population (CCR5 ${ }^{\text {low }}$ ) could be blocked by Met-RANTES first. In this selective property could reside the beneficial effect of MetRANTES compared with the more broad effect of the immunosuppressors previously used in $T$. cruzi-infected individuals that result in increased parasitemia, parasitism and mortality (Andrade et al. 1997, Roffê et al. 2003). Altogether, our results point to the possibility that the intense influx of $\mathrm{CCR}^{+}$leukocytes into the heart tissue during $T$. cruzi infection might be crucial to immunopathogenesis.

Finally, our results support that therapeutic strategies aiming to partial or totally block CC-chemokine signaling via its receptors might become an attractive target for further evaluation during T. cruzi infection, especially in the chronic phase.

\section{REFERENCES}

Aliberti JC, Machado FS, Souto JT et al. 1999. Beta-chemokines enhance parasite uptake and promote nitric oxide-dependent microbiostatic activity in murine inflammatory macrophages infected with Trypanosoma cruzi. Infect Immun 67: 48194826.

Aliberti JC, Souto JT, Marino AP, Lannes-Vieira J, Teixeira MM, Farber J, Gazzinelli RT, Silva JS 2001. Modulation of chemokine production and inflammatory responses in interferon-gamma- and tumor necrosis factor-R1-deficient mice during Trypanosoma cruzi infection. Am J Pathol 158: $1433-1440$

Andrade SG, Carneiro Filho A, de Souza AJ et al. 1997. Influence of treatment with immunosuppressive drugs in mice chronically infected with Trypanosoma cruzi. Int J Exp Pathol 78: 391-399.

Calzada JE, Nieto A, Beraun Y et al. 2001. Chemokine receptor CCR5 polymorphisms and Chagas' disease cardiomyopathy. Tissue Antigens 58: 154-158.

Cook DN, Smithies O, Strieter RM et al. 1999. CD8 ${ }^{+}$T cells are a biologically relevant source of macrophage inflammatory protein-1a in vivo. J Immunol 162: 5423-5428.

D'avila Reis D, Jones EM, Tostes Jr S et al. 1993. Characterization of inflammatory infiltrates in chronic chagasic myocardial lesions: presence of tumor necrosis factor- $\alpha^{+}$ cells and dominance of granzyme $\mathrm{A}^{+}, \mathrm{CD}^{+}$lymphocytes. Am J Trop Med Hyg 48: 637-644.

dos Santos PVA, Roffê E, Santiago HC, Torres RA, Marino APMP, Paiva CN, Silva AA, Gazzinelli RT, Lannes-Vieira J 2001. Prevalence of CD $8^{+} \alpha$ T-cells in Trypanosoma cruzielicited myocarditis is associated with acquisition of CD62LLowLFA-1HighVLA-4High activation phenotype and expression of IFN- $\gamma$-inducible adhesion and chemoattractant molecules. Microbes Infect 3: 971-984.

Fernandez-Mestre MT, Montagnani S, Layrisse Z 2004. Is the CCR5-59029-G/G genotype a protective factor for cardiomyopathy in Chagas disease? Hum Immunol 65: 725728.

Gao JL, Wynn TA, Chang Y et al. 1997. Impaired host defense, hematopoiesis, granulomatous inflammation and type 1type 2 cytokine balance in mice lacking CC chemokine receptor 1. J Exp Med 185: 1959-1968.

Grönne HJ, Weber C, Weber KS et al. 1999. Met-RANTES reduces vascular and tubular damage during acute renal transplant rejection: blocking monocyte arrest and 
recruitment. FASEB J 13: 1371-1383.

Hayashidani S, Tsutsui H, Shiomi T et al. 2003. Anti-monocyte chemoattractant protein-1 gene therapy attenuates left ventricular remodeling and failure after experimental myocardial infarction. Circulation 108: 2134-2140.

Higuchi ML, Reis MM, Aiello VD, Benvenuti LA, Gutierrez PS, Bellotti G, Pileggi F 1997. Association of an increase in $\mathrm{CD}^{+} \mathrm{T}$ cells with the presence of Trypanosoma cruzi antigens in chronic, human chagasic myocarditis. Am J Trop Med Hyg 56: 485-489.

Higuchi ML, Benvenuti LA, Martins Reis M et al. 2003. Pathophysiology of the heart in Chagas' disease: current status and new developments. Cardiovasc Res 60: 96-107.

Lannes-Vieira J 2003. Trypanosoma cruzi-elicited CD8 ${ }^{+}$. T cellmediated myocarditis: chemokine receptors and adhesion molecules as potential therapeutic targets to control chronic inflammation? Mem Inst Oswaldo Cruz 98: 299-304.

Loetscher P, Ugiccioni M, Bodoli L et al. 1998. CCR5 is characteristic of Th1 lymphocytes. Nature 391: 344-345.

Machado FS, Martins GA, Aliberti JCS et al. 2000. Trypanosoma cruzi-infected cardiomyocytes produce chemokines and cytokines that trigger potent nitric oxidedependent trypanocidal activity. Circulation 102: 30033008 .

Marino APMP, Azevedo MIP, Lannes-Vieira J 2003a. Differential expression of adhesion molecules shaping the T-cell subset prevalence during the early phase of autoimmune and Trypanosoma cruzi-elicited myocarditis. Mem Inst Oswaldo Cruz, 98: 945-952.

Marino AP, Silva AA, Pinho RT, Lannes-Vieira J 2003b. Trypanosoma cruzi infection: a continuous invader-host cell cross talk with participation of extracellular matrix and adhesion and chemoattractant molecules. Braz J Med Biol Res 36: 1121-1133.

Marino APMP, Silva AA, dos Santos PVA, Pinto LMO, Gazzinelli RT, Teixeira MM, Lannes-Vieira J 2004. RANTES antagonist (Met-RANTES) controls the early phase of Trypanosoma cruzi-elicited myocarditis. Circulation 110: 1443-1449.

Mckenzie NA 2000. Regulation of T helper type 2 cell immunity by IL-14 and IL-13. Pharmacol Ther 88: 143-151.

Michailowsky V, Silva NM, Rocha CD et al. 2001. Pivotal role of interleukin-12 and interferon-axis in controlling tissue parasitism and inflammation in the heart and central nervous system during Trypanosoma cruzi infection. Am J Pathol 159: 1723-1733.

Plater-Zyberk C, Hoogewerf AJ, Proudfoot AE et al. 1997. Effect of a CC chemokine receptor antagonist on collagen induced arthritis in DBA/1 mice. Immunol Let 57: 117-120.

Proudfoot AE 2002. Chemokine receptors: multifaceted therapeutic targets. Nat Review Immunol 2: 106-115.

Proudfoot AE, Buser R, Borlat F, Alouani S, Soler D, Offord RE, Schroder JM, Power CA, Wells TN 1999. Amino-terminally modified RANTES analogues demonstrate differential effects on RANTES receptors. J Biol Chem 274: 32478-32485.

Proudfoot AE, Power CA, Hoogewerf AJ et al. 1996. Extension of recombinant human RANTES by the retention of the initiating methionine produces a potent antagonist. $J$
Biol Chem 271: 2599-2603.

Proudfoot AE, Power CA, Rommel C, Wells TN 2003. Strategies for chemokine antagonists as therapeutics. Review. Semin Immunol 15: 57-65.

Reis MM, Higuchi ML, Benvenuti LA, Aiello VD, Gutierrez PS, Bellotti G, Pileggi F 1997. An in situ quantitative immunohistochemical study of cytokines and IL- $2 \mathrm{R}^{+}$in chronic human chagasic myocarditis: correlation with the presence of myocardial Trypanosoma cruzi antigens. Clin Immunol Immunopath 83: 165-172.

Roffê E, Silva AA, Marino APMP, dos Santos PVA, LannesVieira J 2003. Essential role of VLA-4/VCAM-1 pathway in the establishment of $\mathrm{CD}^{+} \mathrm{T}$ cell-mediated Trypanosoma cruzi-elicited meningoencephalitis. J Neuroimmunol 142: 17-30.

Russo N, Starobinas N 1991. Macrophage activation and resistance to Trypanosoma cruzi infection. Res Immunol 142: 144-146.

Sallusto F, Lanzavechia A, Mackay CR 1998. Chemokines and chemokine receptors in T-cell priming and Th1/Th2mediated responses. Immunol Today 19: 568-574.

Sorensen LN, Paludan SR 2004. Blocking CC chemokine receptor (CCR1) and CCR5 during herpes simplex virus type 2 infection in vivo impairs host defense and perturbs the cytokine response. Scand J Immunol 59: 321-333.

Talvani A, Ribeiro CS, Aliberti JCS, Michailowsky V, Santos PVA, Murta SMF, Romanha AJ, Almeida IC, Farber J, Lannes-Vieira J, Silva JS, Gazzineli RT 2000. Kinetics of cytokine gene expression in experimental chagasic cardiomyopathy: tissue parasitism and endogenous IFN- $\gamma$ as important determinants of chemokine mRNA expression during infection with Trypanosoma cruzi. Microbes Infect 2: 851-866.

Talvani A, Rocha MOC, Ribeiro AL et al. 2004. Chemokine receptor expression on the surface of peripheral blood mononuclear cells in Chagas Disease. J Infect Dis 189: 214220.

Tarleton RL, Sun J, Zhang L et al. 1994. Depletion of T-cell subpopulations results in exacerbation of myocarditis and parasitism in experimental Chagas' disease. Infect Immun 62: $1820-1829$.

Taub DD, Conlon K, Lloyd AR et al. 1993. Preferential migration of activated $\mathrm{CD}^{+}$and $\mathrm{CD} 8^{+} \mathrm{T}$ cells is response to MIP$1 \alpha$ and MIP-1 $\beta$. Science 260: 355-358.

Teixeira MM, Gazzinelli RT, Silva JS 2002. Chemokines, inflammation and Trypanosoma cruzi infection. Trends Immunol 18: 262-265

Teixeira MM, Wells TNC, LuKac NW et al. 1997. Chemokineinduced eosinophil recruitment. Evidence of a role for endogenous eotaxin in an in vivo allergy model in mouse skin. J Clin Invest 100: 1657-1666.

Vaday G, Franitza S, Schor H et al. 2001. Combinatorial signals by inflammatory cytokines and chemokines mediate leukocyte interactions with extracellular matrix. J Leukoc Biol 69: 885-892.

Villalta F, Zhang Y, Bibb KE, Kappes JC, Lima MF 1998. The cysteine-cysteine family of chemokines RANTES, MIP$1 \alpha$, and MIP-1 $\beta$ induce trypanocidal activity in human macrophages via nitric oxide. Infect Immun 66: 4690-4695. 